\title{
Analysis of Cost Control of Infrastructure Construction in Colleges and Universities on Basis of FIDIC Contract Conditions
}

\author{
Shu-lin Yi \\ NANYANG NORMAL UNIVERSITY, Henan Nanyang in China
}

Keywords: FIDIC contract conditions; Infrastructure construction project; Cost control Abstract. This article first briefly introduced the contract conditions of FIDIC and made the analysis of the present situation of infrastructure projects in colleges and universities.Because of the particularity of colleges and universities in China, the project cost management has been and being geared to the market. In order to ensure the smooth operation of infrastructure projects, cost control problem was discussed according to FIDIC contract conditions, and the specific application of FIDIC contract conditions on infrastructure projects in colleges and universities were analyzed in detail in order to provide a certain level for the relevant technical personnel.

FIDIC contract conditions are contract conditions of civil engineering construction written by Federation International Des Ingenieurs Conseils【1】. FIDIC is an internationalized consultant and management institution which is widely recognized around the world; FIDIC contract conditions are applied by many countries because they suit actual construction and are easy to be implemented; at present, they are mainly used in handling relationships among construction parties; they can restrict all parties' rights and guarantee their profits at the same time; the idea of "human management" is faded; each party is limited according to common laws; the openness and the transparency of projects are assured.

\section{FIDIC Contract Conditions and Current Status of Cost Control of Infrastructure Construction in Colleges and Universities}

Since the end of last century when enrollment system was conducted in Chinese colleges and universities, in order to carry out normal education, teaching and scientific researching work, colleges and universities started large-scale infrastructure construction; because of the particularity of colleges and universities, management problems appear during project process; on one hand, too much money is spend and construction expenses seriously exceed budget; on the other hand, manager's management works are not efficient and cause various wast atmosphere. As widely recognized international customs, FIDIC contract conditions have not been promoted on a large-scale yet for infrastructure construction in Chinese colleges and universities; as Party A units, colleges and universities can apply FIDIC contract conditions as project management support of infrastructure construction projects; FIDIC contract conditions can be used through the whole process of infrastructure construction projects, from design to settlement, so the investment of the whole projects can be fully used and the maximum function of fund can be played. 


\section{Cost Control Measures Applied for Infrastructure Construction in Colleges and Universities According to FIDIC Contract Conditions}

\section{Cost Control Measures Applied on Decision-making Stage by Using FIDIC Contract Conditions}

Firstly, feasibility analysis of projects shall be conducted for new construction and reconstruction projects; scientificity and accuracy of project investment can be assured through the analysis; risks of blind investment can be reduced and the utilization efficiency of project fund can be guaranteed.

Secondly, project proposal jof infrastructure construction in colleges and universities shall be carefully written. Colleges and universities shall combine their practical situations and conduct overall research based on their original plans; research results shall be compared with the original development plans; proper and better project construction plan shall be chosen in accordance with demands; the scientificity and feasibility of preliminary project plan shall be discussed by experts.

Finally, project estimation shall be drawn. It is an important step for decision-making stage and directly affects all aspects of the project, such as scale, investment scale, project process and etc. Following methods can be used to increase the accuracy of investment estimation 【2】:

(1)On the feasibility stage before project construction, initial investment estimation shall be carried out and initial estimation report shall be given in order to assure the scientificity and rationality of investment; (2) Study investment approach and risk investment management approach according to the initial estimation report; (3) Strictly manage engineering projects in accordance with project investment management approach and ensure the smooth operation of projects. On decision-making stage, select the better one after investment budget is done; based on feasibility report of each budget, combine practical situation of infrastructure construction in colleges and universities and overall select the best one from available project plans.

\section{Cost Control Measures Applied on Design Stage by Using FIDIC Contract Conditions}

Design stage of projects is divided into following sections: overall graphic design, technics design, structure design, equipment design and so on. Because there are many design processes, so multi aspects need to be considered in cost control on design stage; overall plans need to be made and all factors shall be paid attention; all round cost control shall be carried out on design stage, following measures can be applied: (1) Conduct quota design according to the approved project investment amount; when design the drawing of an engineering project, scientifically distribute the project investment in accordance with approved investment amount and use it strictly according to distributed amounts; make sure each unit operate normally and amounts do not exceed the budget at the same time. (2) Follow fair, impartial and open principles in project bidding; choose qualified units and make economic and technics evaluations; it is important for rationally choosing project design plan and reducing relevant project costs.

\section{Cost Control Measured Applied on Bidding Stage by Using FIDIC Contract Conditions}

(1) Strengthen audit on bill of quantities. According to relevant terms of FIDIC contract document[2], colleges and universities need to organize related staffs, to audit the bill of quantities of project drawing and to entrust professional project management company for cost consultant; during cost consultant, staffs of colleges and universities need to communicate with staffs of the project management company in order to solve related problems in time. In addition, besides auditing the bill of quantities, infrastructure construction departments of colleges and universities shall also audit bidding documents as well; editing bidding documents is the responsibility of cost consultant companies, but infrastructure construction departments of colleges and universities need to follow the whole process, to combine project situation and to bring about their own demands in 
order to assure the smoothness of future work; the infrastructure construction departments which take charge of large amount of engineering and funds shall pay attention on reviewing work 【3】.

(2) Strengthen bidding evaluation and guarantee the fairness of the evaluation. Before bidding evaluation starts, an important work for infrastructure construction departments is to rationally make project bidding price; they need to make base bidding price rationally according to market price; they can adjust the price within certain time and range, but the price can not be too low so that those construction companies which can not make sure the quality of construction can not win the bidding. During bidding evaluation, if staffs of colleges and universities do not have professional cost knowledge, they shall entrust cost institutions for evaluation. Meanwhile, detailed and true project materials shall be provided to ensure the scienficity of bidding evaluation. Bidding evaluation is not a process in which only total price is checked; various factors and the profits of construction parties need to be considered; the evaluation shall be conducted through combing market price; if the profits are too low, then it means that there must be problems about the project bidding; a rational analysis of unit project bidding price is the core of cost work; engineering companies' advance construction degree, social reputation, economic benefits, scale and other factors shall all be considered; audit of certain expenses, such as measure expense, can show whether a tendering unit use malicious competition means during bidding.

(3) Cost control measures applied on construction stage by using FIDIC contract conditions. According to FIDIC contract conditions, cost control on construction stage requires rational allocation of project organization and related demands of design change. Relevant professional talents need to be imported on construction stage, at the same time, an organization with clear labor division shall be established; units and staffs without clear labor division shall be handled as soon as possible; work requests of each department shall be cleared through making cost work plans. Design change is inevitable in actual project operation process, therefore, try to control design change within the primary period of construction; compare many aspects and then conduct the construction; when there is a design change, built building will be torn down and unnecessary loss will be caused; it is wise to avoid change problems as much as possible; changes suggested by construction parties need special and serious consideration; usually, construction parties regroup the price to assure their own profits.

Cost Control Measure Applied on Completion and Settlement Stage by Using FIDIC Contract

\section{Conditions}

On completion and settlement stage, settlement control can be conducted according to relevant contract terms of FIDIC. It needs to be done in accordance with written bidding documents and related contract demands; existing restraint terms in the contract can ensure the profits of investment parties and prevent contractors from raising prices, moreover, it is good for shortening the audit cycle of auditing institutions; terms in the contract can be extended on basis of clear audit contents of engineering project and cost control. In order to make sure cost control work go on smoothly on settlement stage, audit bidding system shall be carried out fully; selection of auditing unit can greatly affect normal settlement work; a good auditing unit can ensure excellent work and reduce auditing expense at the same time.

\section{Living example of Colleges and Universities capital construction project's cost control according to FIDIC contract condition}

Office building project of Shangdong province X college new campus, its floor space is 3000 square meters, structure area is 16000 square meters. It possesses 6 floor, the first floor 
underground, floor height is $3.0 \mathrm{~m}$, and the project duration is 12 months. Construction party provides project management support for capital construction project strictly according to FIDIC contract condition.

Making investment control in the decision phase. During the process of office building construction, there are two designing institutes provide designing scheme, and this college implements it by choosing a scheme from these two schemes according to the engineering's actual need.

When proceeding the investment estimation for office building, the college leader first establish estimate group, and it carries out the specific estimates for the aspects such as office building's shape, building storey, structure area, floor height, architectural form, water and electricity installation and etc. Through the analysis of this project's investment control, and after this investment estimate has been authenticated as scientific and reasonable according to the experts' discussion, we can proceed the investment according to this investment control.

During the processes of invitation for bids and investment control, the approval investment limit for office building is 34 million yuan. According to the review of construction drawing, the college found that some designs of inner office building are unreasonable, and it can not meet the normal function need, such as the fire protection system design drawing is not conform with the related specification requirements. According to the contract terms' agreement, we adjust the budget, after optimization, the budget is 32.9 million yuan, and it has reduced 1.1 million yuan in contrast with initial investment limit.

In the later period of engineering construction, the construction party put forward the quality method of 4M1E for solving the problems of long construction duration, quality does not conform with the standard, and it mainly includes the engineering material control, the engineering personnel management, construction machinery's storage and management, and the engineering environment management. The specific way as shown in figure 1 , figure 2 .

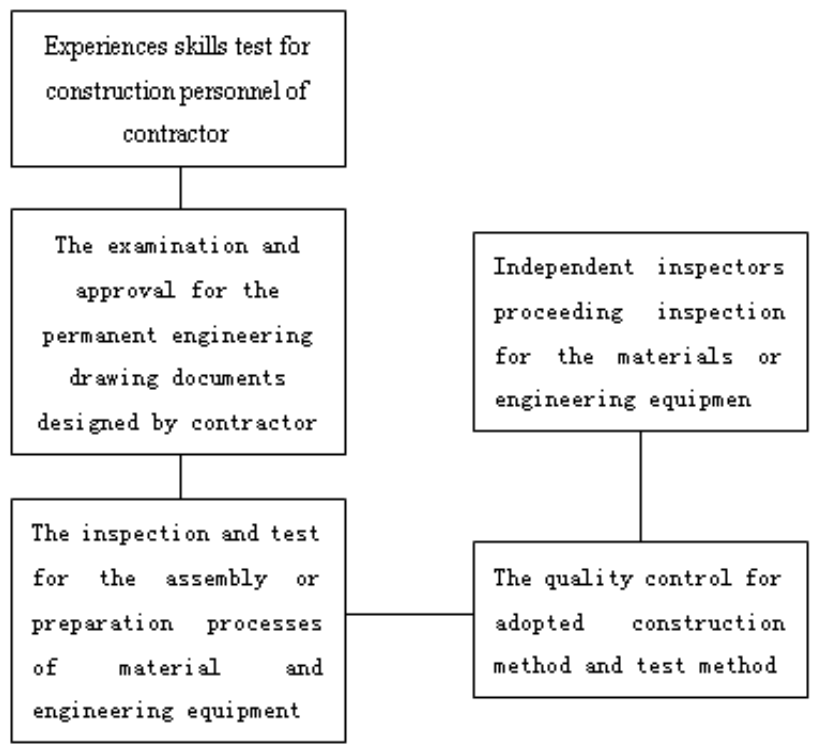

figure 1 


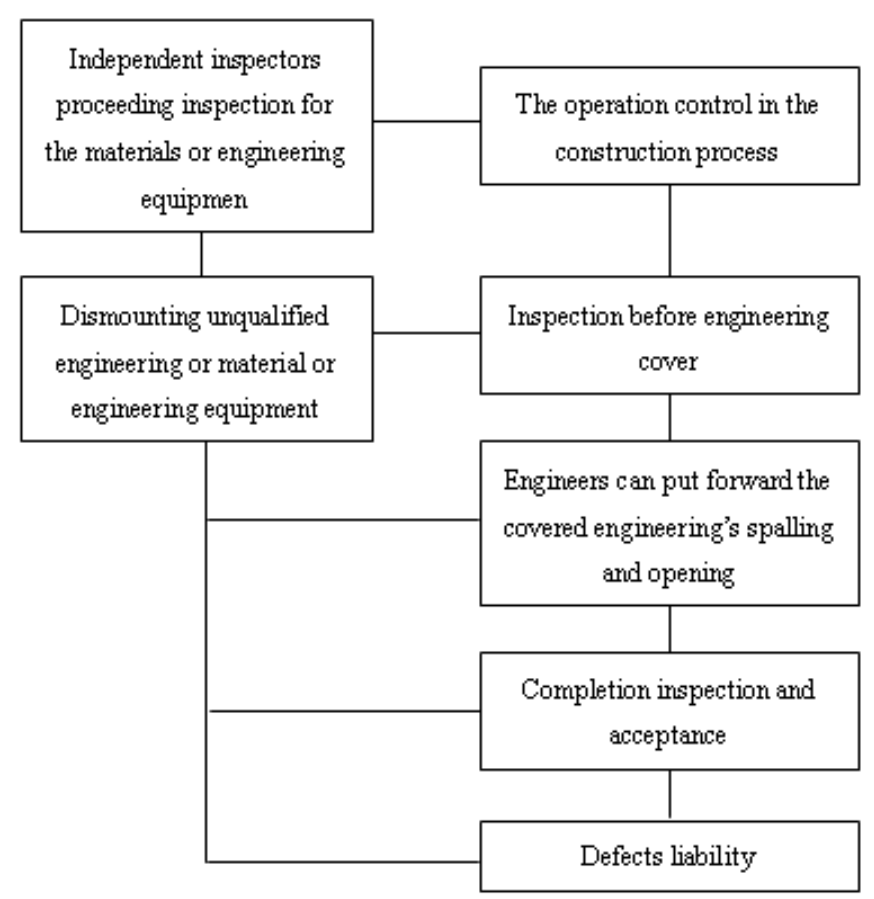

Figure2

Through the capital construction project's control and management under the condition of FIDIC contract, it not only makes the project measures more scientific, engineering estimate cuts, but also the engineering quality gets effectively guarantee. Therefore, there is useful for strengthening the project management and control under the condition of FIDIC contract.

\section{ConclusionAcknowledgements}

Although enrollment in colleges and universities brought big challenges, we need to hold a positive attitude and to apply brand new project management consultant approach in project cost controlling through combing actual development demands of colleges and universities in our country; in this way, a cost control method which suits the requirement of infrastructure construction in colleges and universities can be designed.

\section{ACKNOWLEDGEMENTS}

Thanks for the support of the project "Innovation of university engineering construction management"(NO. 132400410186) from Henan science and Technology Department.

\section{References}

[1] Zongzhi Liu. Study of Project Management of Infrastructure Construction in Colleges and Universities [D]. Hefei University of Technology, 2010.

[2] Hongying Hou. Analysis of Cost Control Problems in the Whole Process of Infrastructure Construction in Colleges and Universities [J]. Journal of Wuhan Institute of Shipbuilding Technology, 2013, 05: 50-52.

[3] Jing Peng. Study of Engineering Claim on Basis of FIDIC Construction Contract Conditions [D]. Dalian University of Technology, 2008. 